\title{
EL CASO ESPAÑOL Y SUS IMPLICACIONES PARA EL ESTUDIO DE LA ULTRADERECHA: ANTECEDENTES Y NUEVAS ESTRATEGIAS DE INVESTIGACIÓN
}

\author{
The Spanish case and its implications \\ for far right studies: Antecedents \\ and new research strategies
}

\author{
PABLO ORTIZ BARQUERO' \\ Universidad Pablo de Olavide \\ portbar@upo.es \\ ANTONIA MARÍA RUIZ JIMÉNEZ \\ Universidad Pablo de Olavide \\ amruiz@upo.es

\section{MANUEL TOMÁS GONZÁLEZ FERNÁNDEZ \\ Universidad Pablo de Olavide \\ mtgonfer@upo.es} \\ Cómo citar/Citation \\ Ortiz Barquero, P., Ruiz Jiménez, A. M. ${ }^{a}$ y González Fernández, M. T. (2020). \\ El caso español y sus implicaciones para el estudio de la ultraderecha: \\ antecedentes y nuevas estrategias de investigación. \\ Revista de Estudios Políticos, 188, 199-220 \\ doi: https://doi.org/10.18042/cepc/rep.188.07
}

Resumen

Este artículo pretende contribuir al corpus teórico existente sobre la ultraderecha, cuyo tema central es la determinación de las condiciones que explican su desempeño electoral (es decir, su éxito o su fracaso). El caso español, que se ha caracterizado

Autor para correspondencia: Pablo Ortiz Barquero. Departamento de Sociología, Universidad Pablo de Olavide de Sevilla. Ctra. de Utrera, km. 1, 41013. Sevilla (España). 
por la ausencia prolongada y, más recientemente, por la irrupción y consolidación de un partido de ultraderecha, es apropiado para tal fin. Por un lado, se revisarán algunas de los planteamientos que han constituido el marco explicativo dominante hasta el momento — el paradigma de la excepcionalidad_-, señalando su bases y debilidades. Al hilo de esta revisión, apoyada con fundamentación empírica, y con base en la reciente irrupción de Vox, se propondrán nuevas estrategias para abordar el estudio de la ultraderecha en España (aplicables también para el examen de este fenómeno político en perspectiva comparada). Estas vías alternativas tienen dos implicaciones cruciales: otorgar un papel preeminente a las teorías de la oferta en el esquema explicativo y colocar a los partidos de ultraderecha en el centro de la discusión.

\section{Palabras clave}

España; ultraderecha; estudios de caso; teorías de la oferta; teorías de la demanda.

\section{Abstract}

The aim of this article is to contribute to the theoretical frame about far right, which is focused on the conditions that affect its electoral performance. Spain case is especially suitable to investigate the performance of this family of parties because far right has been irrelevant since the end of Francoist dictatorship to 2018, when an electoral breakthrough was led by Vox. First, hegemonic explanations about the Spanish case — defined as the exceptionalism paradigm — will be analysed using a critical glass. Through empirical substantiation, new research strategies will be proposed to study far right in Spain (also of interest to conduct comparative research). These alternative strategies have two main implications. On one hand, the research agenda should give more importance to supply-side theories. On the other, it is necessary to situate far right parties at the centre of explanations.

\section{Keywords}

Spain; far right; case studies; supply-side theories; demand-side theories. 


\section{SUMARIO}

I. INTRODUCCIÓN. II. LA ULTRADERECHA EN ESPAÑA: EVOLUCIÓN Y CARACTERIZACIÓN IDEOLÓGICA (1977-2019). III. ¿̇DE QUÉ HABLAMOS CUANDO HABLAMOS DE ULTRADERECHA? HACIA UN MARCO CONCEPTUAL OPERATIVO. IV. TEORÍAS DOMINANTES SOBRE EL CASO ESPAÑOL: EL PARADIGMA DE LA EXCEPCIONALIDAD: 1. Teorías de la demanda. 2. Teorías de la oferta. V. LOS LÍMITES DEL PARADIGMA DE LA EXCEPCIONALIDAD. VI. NUEVAS ESTRATEGIAS DE INVESTIGACIÓN PARA EL ESTUDIO DE LA ULTRADERECHA EN ESPAÑA. BIBLIOGRAFIA.

\section{INTRODUCCIÓN}

España ha sido durante mucho tiempo considerada un caso desviado al ser uno de los pocos escenarios en Europa - junto con Portugal ${ }^{2}$ e Irlandaen el que ninguna fuerza de ultraderecha ocupaba un lugar relevante en el sistema político (Alonso y Rovira, 2015). Así, desde el inicio del régimen democrático ha ido cristalizando un determinado marco explicativo hegemónico que asumía la excepcionalidad del caso español, afirmando el carácter refractario de España respecto a este fenómeno político. La influencia de este paradigma ha ido más allá del plano académico, arraigado profundamente también a nivel sociopolítico entre la ciudadanía y los partidos. Sin embargo, la irrupción de Vox en diferentes arenas electorales a finales de 2018 ha puesto en cuestión las bases del paradigma de la excepcionalidad.

El objetivo principal de esta nota bibliográfica es revisar de forma crítica los marcos explicativos dominantes sobre la ultraderecha en España, señalando algunos de sus déficits teóricos y empíricos y proponiendo una serie estrategias alternativas para acometer el estudio de dicho fenómeno político. Atender al caso español, cuya ultraderecha ha tenido un impacto muy desigual en perspectiva histórica, supone evitar el sesgo de selección que caracteriza a buen aparte de la literatura, centrada casi mayoritariamente en los casos exitosos (Norris, 2015: 108). Los avances más recientes coinciden en apuntar el potencial explicativo de los casos fallidos para entender las condiciones que obstaculizan o posibilitan la institucionalización de este tipo de partidos (Acha, 2017a). Esto implica considerar fracaso y éxito como escenarios

2 En octubre de 2019 el partido CHEGA consigue un escaño en el Parlamento, si bien la ultraderecha continúa siendo marginal en Portugal. 
interrelacionados, integrándolos como categorías operativas en un marco explicativo que tenga por finalidad elaborar una teoría de medio-largo alcance sobre los partidos de ultraderecha.

Se usarán principalmente fuentes secundarias cuyo examen simultáneo permitirá el rastreo exhaustivo de los marcos explicativos hegemónicos sobre la ultraderecha en España. A partir de esta fundamentación empírica se llevará a cabo un análisis crítico de dichos marcos para para identificar y deconstruir varias de sus asunciones. Se parte de la base de que algunos de estos planteamientos poseen ciertos sesgos y debilidades, no encontrando un apoyo pleno en el plano empírico. En este sentido, se apuntará un conjunto de estrategias de investigación alternativas que tengan en cuenta la multicausalidad y la complejidad del fenómeno en cuestión y que pueda superar el reduccionismo y el carácter estático de algunos de los enfoques precedentes. Se persigue, por un lado, contribuir al estudio de la ultraderecha en Espańa por medio de la propuesta de un marco teórico-analítico más refinado, y por otro, enriquecer la discusión general - desde un punto de vista comparativo - acerca de las condiciones y mecanismos que explican el desempeño de la ultraderecha.

\section{LA ULTRADERECHA EN ESPAÑA: EVOLUCIÓN Y CARACTERIZACIÓN IDEOLÓGICA (1977-2019)}

En primer lugar, se realizará un examen de las dinámicas de la ultraderecha española desde el final de la dictadura franquista hasta la actualidad. A través de un enfoque historicista puede aprehenderse el rasgo fundamental de este fenómeno político: su desigual rendimiento temporal y geográfico.

Tras la muerte de Franco, la ultraderecha se encontró con un escenario sumamente adverso y sus diferentes familias ideológicas, acomodadas durante largo tiempo en las diferentes instancias de la dictadura, representaron desde un primer momento el actor más reaccionario e involucionista del proceso de Transición. La ultraderecha mantuvo una postura muy activa, con demostraciones de fuerza en forma de manifestaciones multitudinarias (Rodríguez, 1997). Consignas como «iLarga vida al 18 de julio!» o «Franco resucita, España te necesita» evidenciaban el ensalzamiento absoluto de la dictadura y los recelos ante las concesiones aperturistas (Gilmour, 1992).

Sin embargo, la Transición seguía su curso en buena medida porque las élites franquistas moderadas, asumiendo el inexorable final del régimen, decidieron iniciar un desmantelamiento controlado del mismo por medio de la Ley para la Reforma Política (1976). Si bien es cierto que los actores democráticos jugaron un importante papel, la Transición no puede entenderse sin la actuación de los sectores moderados del franquismo, que supieron hábilmente pilotar el 
proceso e integrarse en el nuevo marco democrático. Además, las fuerzas democráticas ofrecieron garantías a los responsables de la dictadura de no ser juzgados por sus actos, cristalizándose una suerte de "pacto del olvido» (Aguilar, 2001).

En este contexto de cambio la ultraderecha se encontraba tensionada entre dos polos: incidir en los postulados reaccionarios y explícitamente autoritarios o participar del nuevo marco democrático. Más por necesidad que por convencimiento, buena parte de la ultraderecha decide optar por la segunda opción, con la idea de que el denominado franquismo sociológico le reportaría réditos electorales. No obstante, diversos factores obstaculizaban el acomodo de la ultraderecha.

En primer lugar, hay que considerar la atomización y fraccionamiento del universo ideológico de la ultraderecha. Solo en el ámbito ideológico del falangismo ${ }^{3}$ es posible encontrar decenas de partidos que intentan rentabilizar las siglas históricas de Falange. Sin embargo, las divisiones ideológicas y personales impiden al falangismo elaborar una oferta política viable. Ni siquiera FE de las JONS (Auténtica), la organización con más fortaleza, consigue aglutinar militancia u obtener respaldo social (Rodríguez, 1997).

Por otro lado, hay que considerar que buena parte de las élites franquistas van a integrarse en Alianza Popular (AP) y Unión de Centro Democrático (UCD). En particular, AP desempeña durante su primera etapa el papel de canalizador del neofranquismo renovado. Su capacidad para integrar a los cuadros franquistas, seducir al franquismo sociológico y, progresivamente, mutar desde posiciones de ultraderecha hasta postulados más cercanos a los de una derecha democristiana, contribuyeron a desactivar las posibilidades electorales de la ultraderecha (Rodríguez, 1992). En este sentido, del Río (2013) apunta que el caso de AP (después Partido Popular - PP—) resulta excepcional en cuanto que se trata del único partido hegemónico de centroderecha europeo cuyos orígenes se encuentran explícitamente en el universo de la ultraderecha.

En las elecciones constituyentes la ultraderecha no consigue representación; sin embargo, en 1979 Fuerza Nueva $(\mathrm{FN})$ —liderando la coalición Unión Nacional- obtiene 378964 votos y un escaño en el Congreso. Este escaño es ocupado por Blas Pińar, figura distinguida del régimen franquista con considerable carisma y dotes oratorias. FN representa una clara continuación de los

3 El falangismo nace a finales de los años veinte del s. xx y es considerado — aun con sus particularidades - la expresión del fascismo en el contexto español. Durante el franquismo los sectores falangistas fueron perdiendo progresivamente peso en el régimen, tras una primera etapa con notable influencia. Como tal, el falangismo presenta rasgos como el antiliberalismo, antimarxismo, ultranacionalismo palingenésico o culto a la violencia y la juventud. Para profundizar, véase Ruiz-Carnicer (2013). 
valores franquistas: un planteamiento conservador, ultranacionalista, autoritario y de matriz católica (Rodríguez, 1992; Fuerza Nueva, 1976).

Sin embargo, la aspiración de consolidación de FN se evapora en 1982, no consiguiendo obtener representación y desapareciendo justo ese ańo. Respecto a las causas que explican su fallido proceso de institucionalización, Casals (2009) apunta, por un lado, a la incapacidad para construir una organización sólida organizativa e ideológicamente: prueba de ello sería el excesivo personalismo en torno a Piñar y el hecho de que nunca elaborara un programa electoral detallado. Al mismo tiempo, el partido no supo resolver la tensión interna: mientras la dirección era partidaria de incorporarse al sistema democrático, los sectores jóvenes querían avanzar en la línea de "partido antisistema» (Rodríguez, 1997: 448-449).

Tras la desaparición de FN, la ultraderecha afronta una larga etapa la que se acentúa su atomización y falta de estrategia organizativa e ideológica. El empeño por continuar con el discurso autoritario y ligado al franquismo resultó infructuoso, así como los intentos de reproducir el modelo de la derecha radical populista que comenzaba a cosechar buenos resultados en Europa. Ninguna de las opciones renovadoras fructificó: ni en la vertiente más tradicional (Juntas Españolas), ni en la más moderna de corte populista (Democracia Nacional o España 2000). Esta suerte de travesía en el desierto se prolongó durante las décadas de los ochenta y noventa.

A principios de los 2000, un partido de ámbito catalán —Plataforma per Catalunya $(\mathrm{PxC})$ - gana una considerable presencia electoral a nivel local. $\mathrm{PxC}$ articula un discurso nativista, populista y autoritario (explotando, sobre todo, el nativismo basado en la islamofobia), al tiempo que mantiene una deliberada ambigüedad en el eje centro-periferia con objeto de desmarcarse del ultranacionalismo español que ha estigmatizado a la ultraderecha española tradicionalmente (Hernández-Carr, 2012; Llamazares, 2012). PxC puede considerarse la primera experiencia española capaz de trasladar el modelo europeo de derecha radical populista (eso sí, con una influencia limitada, ya que el partido es incapaz de expandirse más allá del ámbito catalán) ${ }^{4}$.

En 2013, un grupo de personalidades ligadas al entorno ideológico y organizativo del PP decide construir una nueva opción política, descontentos ante lo que entienden es una deriva del PP hacia la moderación. Así nace Vox, un partido situado inequívocamente en la familia de la ultraderecha y cuyos ejes ideológicos son el ultranacionalismo español (en particular, la defensa de

4 Fruto del declive electoral a partir de 2011, del faccionalismo y la falta de solidez organizativa, PxC termina desapareciendo en 2019, integrándose gran parte de sus bases en Vox. 
la unidad de España y el reclamo de una organización territorial centralista) y los planteamientos antiinmigración y antifeministas (Sánchez-Cuenca, 2018; Acha, 2019). En sus primeros ańos, los resultados de Vox son exiguos y no será hasta finales de 2018 cuando protagonice una irrupción en las elecciones andaluzas consiguiendo doce diputados (ver tabla 1). A partir de este momento, y aprovechando un ciclo electoral bastante atípico (en el que coinciden cinco comicios en pocos meses), consigue instalarse en la arena política, logrando en poco tiempo uno los hitos más aceptados para calificar el éxito de los partidos: superar el $5 \%$ en dos o tres elecciones consecutivas (Art, 2011). La irrupción de Vox, a expensas de su evolución a medio-largo plazo, supone un hecho de gran interés, dado que es la primera vez en todo el régimen democrático que un partido de ultraderecha tiene éxito.

Tabla 1. Resultados electorales de Vox (2014-2019)

\begin{tabular}{lccc}
\hline Elecciones & Votos & \% votos & Representación \\
\hline Parlamento europeo (mayo 2014) & 246.833 & 1,57 & 0 \\
\hline Parlamento de Andalucía (marzo 2015) & 18.017 & 0,45 & 0 \\
\hline Elecciones municipales (mayo 2015) & 50.195 & 0,25 & 22 \\
\hline Elecciones autonómicas (mayo 2015) & 74.531 & $\begin{array}{c}0,39 \\
\text { (media) }\end{array}$ & 0 \\
\hline Elecciones generales (diciembre 2015) & 58.114 & 0,23 & 0 \\
\hline Elecciones generales (junio 2016) & 47.182 & 0,2 & 0 \\
\hline Parlamento de Andalucía (diciembre 2018) & 395.978 & 10,97 & 12 \\
\hline Elecciones generales (abril 2019) & 2.677 .173 & 10,25 & 24 \\
\hline Cortes Valencianas (abril 2019) & 278.947 & 10,44 & 10 \\
\hline Elecciones municipales (mayo 2019) & 669.736 & 2,9 & 530 \\
\hline Elecciones autonómicas (mayo 2019) & 684.312 & $\begin{array}{c}5,74 \\
(\text { media) }\end{array}$ & 27 \\
\hline Parlamento europeo (mayo 2019) & 1.388 .681 & 6,2 & 3 \\
\hline
\end{tabular}

Fuente: elaboración propia a partir de datos del Ministerio del Interior.

En resumen, del análisis histórico de la ultraderecha en España se desprende que su desempeño durante el actual régimen democrático ha sido muy desigual. Durante una primera etapa, que abarca desde la Transición hasta finales de 2018, 
la ultraderecha no ha conseguido tener éxito, limitándose sus cortos espacios de influencia a arenas políticas localizadas. No obstante, a partir de 2018, con la irrupción de Vox en diferentes arenas de competición, la ultraderecha logra por primera vez alcanzar cierta consolidación y estabilización. El caso español muestra de forma muy clara la pauta que caracteriza a esta familia de partidos en Europa: la enorme variabilidad temporal y geográfica de su desempeño electoral.

\section{III. ¿̇DE QUÉ HABLAMOS CUANDO HABLAMOS DE ULTRADERECHA? HACIA UN MARCO CONCEPTUAL OPERATIVO}

Hasta el momento, se ha abordado la evolución histórica de la ultraderecha en España señalando su desigual rendimiento electoral como rasgo característico. A continuación, se realizará un breve repaso de las principales discusiones teóricas sobre la materia y se propondrá un marco conceptual de referencia en base a su operatividad.

Desde los ochenta, toda una serie de actores situados en el polo derecho del espectro ideológico ha ido ganando un creciente protagonismo, al hilo de la llamada "tercera ola» de extremismo en Europa (Acha, 2017b). Esta familia de partidos puede ser considerada como la más exitosa surgida en la Europa de posguerra. Aunque hay quienes la consideran una de las mayores amenazas para las democracias contemporáneas, otras voces apuntan que la atención que recibe es desproporcionada y recomiendan no sobredimensionar sus éxitos.

La naturaleza compleja de este fenómeno ha motivado que uno de los principales esfuerzos haya sido el de definirlo con claridad. Lejos de existir consenso, la literatura sobre la materia aparece atravesada por una auténtica "guerra terminológica», en palabras de Mudde (1996). Paradójicamente, este conflicto conceptual ha contribuido a enriquecer el corpus teórico sobre la ultraderecha, como ha señalado Arzheimer (2018).

Una de las propuestas más atractivas es la de Ignazi (2003), al establecer una distinción entre la extrema derecha tradicional y la nueva extrema derecha. La diferencia entre ambas es que la primera conserva un vínculo explícito con el fascismo ${ }^{5}$, mientras que la segunda no (o lo hace de forma débil). Griffin apunta cómo esta nueva corriente representa una amenaza mucho más notable que la vinculada a la tradición fascista, ya que «[...] el liberalismo etnicista ha reemplazado al fascismo como la forma de derecha radical mejor adaptada a las realidades del mundo moderno» (2000: 174).

5 Se considera el fascismo clásico como aquella ideología basada en el ultranacionalismo palingenésico y antidemocrático, el unitarismo del sistema político y el uso de la violencia institucionalizada contra los considerados enemigos de la patria (Antón, 2009). 
Por otro lado, Mudde plantea que la clave para explicar la naturaleza distintiva de ambas corrientes radica en los conceptos de extremismo y radicalismo: mientras que el extremismo es plenamente antidemocrático en el sentido de rechazar los principios democráticos básicos, el radicalismo acepta el marco de la democracia liberal (aunque es contrario a algunos de sus pilares) (2010: 1168-1169). Establecida esta matización, plantea una distinción entre la extrema derecha y la derecha radical: «La derecha radical es nominalmente democrática, aunque se oponga a alguno de los valores fundamentales de las democracias liberales, mientras que la extrema derecha es esencialmente antidemocrática, al oponerse al principio fundamental de la soberanía del pueblo» (Mudde, 2007: 31).

En el marco de la corriente de la derecha radical ha ido surgiendo en las últimas décadas un subtipo autónomo, la derecha radical populista, que exhibe tres características ideológicas principales: nativismo, autoritarismo y populismo (Mudde, 2007). De estos tres elementos, el nativismo — simbiosis entre nacionalismo y xenofobia que alude a la primacía del grupo nativo sobre los elementos no nativos y que se asienta en una concepción étnica del Estado- constituye el núcleo central.

Aun considerando estas precisiones taxonómicas previas, en lo sucesivo se usará de manera general el término ultraderecha para denominar al conjunto de esta familia de partidos. Tal y como sostiene Acha (2017a), este término tiene la ventaja de ser más inclusivo y operativo, ya que no pretende determinar ni la fuerza del vínculo con la tradición fascista ni el compromiso con la democracia liberal. El término ultraderecha remite simplemente a la ubicación de este tipo de partidos en el extremo derecho del especto ideológico. Su uso va en la línea de dejar atrás la guerra terminológica que ha lastrado a buena parte de los estudios sobre la materia y que, en ocasiones, ha generado debates hasta cierto punto estériles.

En definitiva, el espacio ideológico existente más allá del centroderecha está ocupado principalmente por la familia de la ultraderecha. Esta familia partidista, que contiene a su vez dos corrientes diferenciadas (extrema derecha y derecha radical), ha ganado un creciente protagonismo en las últimas décadas, generando una enorme atención académica y mediática.

\section{TEORÍAS DOMINANTES SOBRE EL CASO ESPAÑOL: EL PARADIGMA DE LA EXCEPCIONALIDAD}

Como se ha visto, la evolución de la ultraderecha en España ha estado marcada por un extenso periodo de irrelevancia y, más recientemente, por la irrupción electoral protagonizada por Vox. En este apartado se examinarán 
algunos de los marcos explicativos dominantes utilizados para abordar el estudio de la ultraderecha espańola y, en concreto, del periodo de su ausencia y marginalidad.

En primer lugar, cabe señalar que la escasa literatura especializada sobre la ultraderecha en España aparece dominada por una perspectiva historiográfica. Estudios como los de Rodríguez (1992), Casals (1994) o Duñaiturria (2017) ofrecen una excelente panorámica sobre la evolución de la ultraderecha tras la dictadura. Por otro lado, destaca un pequeño grupo de trabajos que, en forma de estudios de caso, profundizan en partidos como $\mathrm{PxC}$ o España 2000 (Hernández-Carr, 2012; López, 2017). No obstante, no existe hasta el momento ninguna aproximación sociológica o politológica que de forma sistemática considere la ultraderecha española como unidad de análisis con objeto de establecer las causas de su desigual desempeño.

En paralelo al crecimiento de esta familia de partidos en Europa desde los años ochenta, el caso español pronto fue definido como una incógnita y excepción. De cara a explicar la ausencia de una ultraderecha exitosa en España se fue asentando un enfoque interpretativo dominante que aquí pasará a denominarse paradigma de la excepcionalidad y que descansa sobre las teorías de la demanda y de la oferta.

\section{TEORÍAS DE LA DEMANDA}

El denominado marco de la excepcionalidad bebe fundamentalmente de las teorías de la demanda, que son aquellas que intentan explicar el rendimiento de la ultraderecha con base en las actitudes, emociones y preferencias del electorado (Rydgren, 2007). El hilo conductor de estas explicaciones es la asunción de que la ultraderecha se ve beneficiada en contextos de crisis económica, polarización y descontento social. Estos planteamientos hunden sus raíces en los estudios clásicos de inspiración marxista y corte psicoanalítico que analizaron el surgimiento del fascismo en la Europa de entreguerras ${ }^{6}$.

Tomando como referencia las teorías de la demanda, se fueron explorando para el caso español algunas de las condiciones socioestructurales que, de entrada, predecirían el éxito de la ultraderecha. Por un lado, está el hecho de que España recibiera durante la década de los 2000 un gran número de inmigrantes como consecuencia de una etapa de bonanza económica: de hecho, en el periodo 2000-2009 Espańa recibe la mitad de los inmigrantes de toda la UE-15, tal y como apunta González-Enríquez

6 Véase Reich (1972) y Adorno et al. (1969). Las fechas originales son, respectivamente, 1933 y 1950. 
(2017: 3). Según el INE, la población extranjera pasa de 637085 a 5648671 entre 1998 y 2009 (INE).

Paralelamente al aumento de la inmigración durante este periodo, se produjo un cambio en las orientaciones de la población: desde actitudes más favorables hasta posturas más hostiles. En el año 2006, la inmigración era concebida como el principal problema de España para el $49 \%$ de la sociedad, de acuerdo con la serie «Tres problemas principales que existen actualmente en España», del CIS. No obstante, durante este periodo - y en perspectiva comparada-, la evidencia empírica muestra que los españoles no eran ni más ni menos tolerantes con la inmigración que el resto de Europa: de hecho, Alonso y Rovira demuestran con datos de la Encuesta Social Europea de 2006 que la población española se sitúa justo en la media europea respecto a las actitudes ante la inmigración (2015: 31).

\section{Gráfico 1. \% respuesta "El número de inmigrantes que hay en España es excesivo" (2008-2017)}

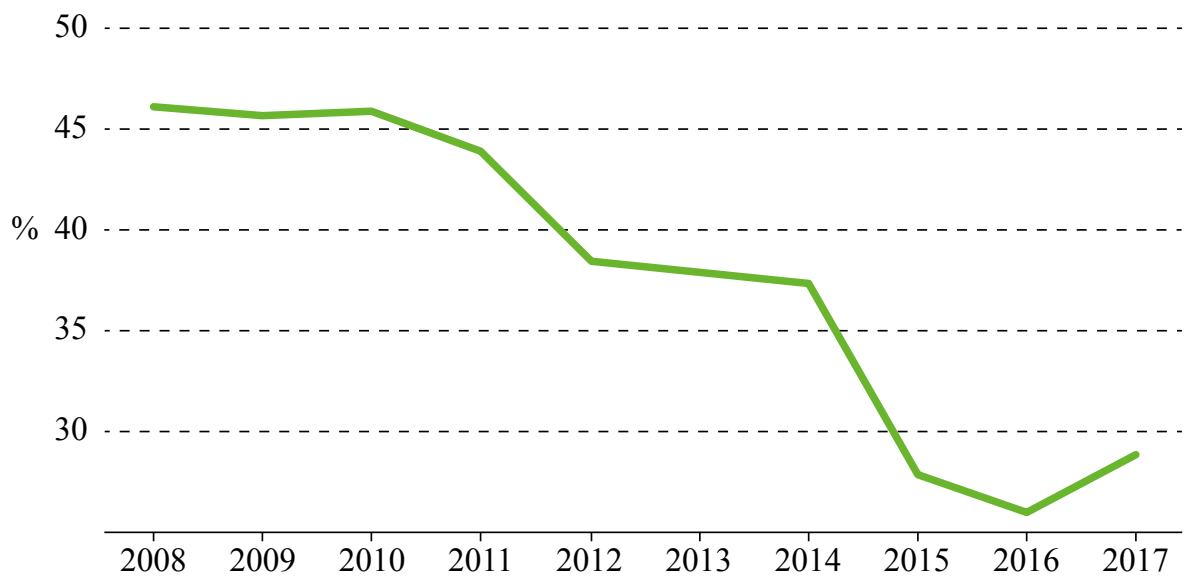

Fuente: elaboración propia a partir de estudios CIS: 2773, 2817, 2846, 2918, 2967, 3019, 3119, 3161 y 3190 .

El aumento de la inmigración se detiene con el comienzo de la Gran Recesión en 2008, en gran medida como resultado de la quiebra de sectores como el de la construcción (uno de los principales nichos laborales para la población inmigrante). Entre 2008 y 2015 Espańa muestra algunos de los peores indicadores económicos de la zona euro: por ejemplo, según el INE la tasa de paro a principios de 2013 alcanza el 27\%. Aunque Espańa es uno de los países más afectados por la crisis económica, esto no se traduce en un 
aumento del sentimiento antiinmigración (gráfico 1), tal y como prevén algunas de las principales teorías al respecto (en particular, la teoría de competencia grupal, que plantea que en un contexto de dificultad económica se esperaría un aumento de los prejuicios sobre la población inmigrante si esta tuviera una presencia notable en la sociedad). Autores como Rinken (2016) demuestran que durante la Gran Recesión los sentimientos antiinmigración se mantuvieron estables e incluso disminuyeron en algunos momentos.

De forma paralela a la crisis económica, el sistema político e institucional afronta una crisis de legitimidad que se traduce en un incremento de la desafección y la desconfianza ciudadana. Sin duda, el punto de inflexión de este proceso es el denominado $15-\mathrm{M}$, un movimiento social de corte ciudadanista que inicia en 2011 un ciclo de movilización en torno al cuestionamiento de la élite político-económica y la demanda de democracia directa. Es aquí donde se encuentran las raíces organizativas e ideológicas de Podemos: cuando un grupo de figuras vinculadas al mundo académico y al activismo realiza un diagnóstico de la situación y entiende que existe espacio para impulsar un partido de izquierda radical populista (Gómez-Reino y Llamazares, 2018). En gran medida, que la responsabilización de la crisis se dirigiera hacia las élites puede explicar parcialmente que los sentimientos antiinmigración no crecieran durante este periodo.

En suma, la literatura identifica para el caso de España desde finales de los años noventa algunas de las condiciones socioestructurales que, de acuerdo con el paradigma hegemónico de corte psicologicista representado por algunas de las teorías de la demanda, preverían un desempeño exitoso de la ultraderecha. Es decir, se valida la existencia de factores asociados a las principales teorías de la demanda: las tesis de la protesta, de la desintegración social, de la crisis económica, de la desintegración y de la temática única.

\section{TEORÍAS DE LA OFERTA}

Las teorías de la oferta, que se centran en la estructura de oportunidades políticas y en las características de los propios partidos, han tenido un papel más modesto en comparación con las de la demanda, aunque han sido igualmente cruciales para la conformación del paradigma de la excepcionalidad.

Una de las principales teorías desde el plano de la oferta es aquella que establece la importancia de los distintos legados históricos y contextos nacionales para explicar la fuerza de los partidos de ultraderecha Desde este punto de vista, se asume que la ultraderecha tendrá menor éxito y posibilidad de presentarse con legitimidad en países marcados por un pasado totalitario o autoritario (Art, 2011). Las trayectorias históricas nacionales afectan al modo en que las subculturas nacionalistas se proyectan organizativa e ideológicamente: en países 
con un pasado marcado por el fenómeno fascista se asume que la ultraderecha tiene menos opciones para presentarse como una opción creíble.

La perspectiva de las tradiciones nacionales ha jugado un papel muy importante a la hora de explicar la sostenida irrelevancia de la ultraderecha en España. Así, se ha planteado que el legado de la dictadura franquista ha actuado como una especie de dique de contención al crecimiento de la ultraderecha, habida cuenta del descrédito y rechazo de la sociedad española a la dictadura (Ruzza, 2018). Aunque a finales de los años noventa la ultraderecha española inicia un proceso de renovación ideológica en un intento por desprenderse de la influencia de la dictadura, los resultados de este proceso han sido infructuosos y buena parte de la sociedad ha seguido vinculando simbólicamente a la ultraderecha con el franquismo (Llamazares, 2012). A su vez, el recuerdo de la dictadura, asentada en un nacionalcatolicismo centralista y unitario, ha contribuido al descrédito del nacionalismo español, como ha señalado de forma exhaustiva la literatura (Muñoz, 2008).

Por otro lado, con respecto a la estructura de oportunidades políticas también se ha aludido al papel del centroderecha consolidado a la hora de explicar el extenso periodo de irrelevancia de la ultraderecha. Se ha evidenciado empíricamente cómo el PP ha sabido atraer a los sectores del electorado más escorados a la derecha, potenciales votantes de una opción de ultraderecha (Llamazares y Ramiro, 2006). A su vez, se ha apuntado cómo la centralidad del eje centro-periferia en la competición política ha penalizado tradicionalmente a la ultraderecha española, impidiéndole jugar con éxito la carta nativista. Es decir, el conflicto entre el nacionalismo estatal y los periféricos ha hecho que la problemática haya girado en torno al plano identitario y territorial y no tanto sobre la inmigración (terreno tradicionalmente más favorable para la ultraderecha) (Alonso y Rovira, 2015). Este escenario ha sido determinante no solo durante el largo periodo de irrelevancia de la ultraderecha, sino también el modo en que esta ha aflorado recientemente.

Por último, también se han apuntado varios factores relacionados con el plano interno y organizativo para explicar la irrelevancia sostenida de la ultraderecha en España. Por un lado, se ha aludido al hecho de que desde Piñar la ultraderecha en España haya carecido de un liderazgo carismático y sólido (Duñaiturria, 2017). Asimismo, se ha apuntado a la atomización partidista y la falta de estructuras organizativas sólidas como rémoras históricas. No obstante, la cuestión de la organización interna y su influencia en el desempeño de la ultraderecha es algo infraestudiado en la temática, en general, y en el caso español, en particular.

En resumen, las teorías de la oferta también han sido utilizadas para abordar el escenario de fracaso de la ultraderecha en España y conformar el paradigma de la excepcionalidad. En particular, este paradigma hegemónico 
ha otorgado gran peso al pasado dictatorial, asumiendo que el rechazo actual hacia el mismo haría inviable cualquier opción de ultraderecha.

\section{LOS LÍMITES DEL PARADIGMA DE LA EXCEPCIONALIDAD}

Como se ha visto, la ausencia sostenida de una opción de ultraderecha exitosa en España ha contribuido a la conformación del denominado paradigma de la excepcionalidad, configurado por explicaciones enmarcadas en las teorías de la demanda y la oferta. A la luz de la irrupción y estabilización de Vox en la arena política, varias de las asunciones de este paradigma se han revelado como insuficientes para abordar el fenómeno en cuestión (esto es, el desigual desempeño de la ultraderecha en España).

Por un lado, el paradigma de la excepcionalidad adolece de un déficit ampliamente identificado en la literatura: adjudicar un peso decisivo a las teorías de la demanda, de tal manera que la simple presencia de ciertas condiciones socioestructurales es interpretada como un factor precipitante que ha de conducir de forma necesaria al éxito de la ultraderecha. En este caso, esta visión determinista respecto a las teorías de la demanda ha operado del siguiente modo: primero, se confirma la presencia de diversos factores asociados al éxito de la ultraderecha (desempleo, crisis económica, protesta, inmigración); y acto seguido, al constatar su fracaso real, se pasa a colegir una especie de excepcionalidad por la cual España estaría inmunizada o vacunada ante este fenómeno político.

Sin embargo, al asumir esta orientación mecanicista se corre el riesgo de contar «una historia relativamente simple sobre el auge de la derecha radical en la que las transformaciones estructurales masivas - postindustrialización, inmigración, globalización o integración europea - generaron una reacción uniforme y predecible» (Art, 2011: 5). Los avances más recientes coinciden en apuntar que el peso de los factores de la demanda no sería tan determinante, sino que operarían más bien como coadyuvadores de los de la oferta. Así, se ha demostrado empíricamente que no existe una relación tan clara - tal y como acríticamente se suele asumir- entre las crisis económicas y el auge de este tipo de partidos (Mudde, 2007; Acha, 2017b). La irrupción de Vox es en este sentido refutadora (ya que ha tenido lugar cuando muchos de los factores identificados con anterioridad son mucho menos prominentes) y apunta a la necesidad de ponderar más equilibradamente el peso de los factores de la demanda.

Por otro lado, en lo que respecta a las teorías de la oferta, el paradigma de la excepcionalidad ha otorgado un papel crucial al pasado dictatorial en España, como si el recuerdo y descrédito del régimen franquista entre la 
población fuera un factor que por sí mismo impidiera a la ultraderecha tener éxito (González-Enríquez, 2017). Aun siendo un argumento plausible que probablemente haya tenido su importancia (sobre todo en la etapa inicial del régimen democrático, cuando las posibilidades de regresión estaban abiertas), lo cierto es que no se detalla con exactitud cómo opera dicho mecanismo. En términos comparativos, la presencia de destacados partidos de ultraderecha en países que padecieron regímenes totalitarios o autoritarios (Alemania, Italia, Hungría o Grecia) parecería aconsejar poner en cuarentena esta hipótesis. No hay que olvidar que, como apunta Eatwell (2003: 63), «las tradiciones nacionales actúan más como factores facilitadores que como factores causales».

Además, el pasado dictatorial bien pudiera ser obstáculo para aquellos partidos que tienen un vínculo explícito con la tradición fascista, pero no tanto para la corriente representada por la derecha radical, cuyo discurso más modernizado rehúye estratégicamente identificarse con ese imaginario. Este es precisamente el caso de Vox —enmarcado en la sub-familia de la derecha radical (Acha, 2019)_, que rehúsa y procura evitar en la medida de lo posible una conexión explícita con el franquismo, instalándose en una medida ambigüedad.

El paradigma de la excepcionalidad también ha subrayado que el legado de la dictadura ha sido una de las causas que han generado el descrédito del nacionalismo español, de forma que la identidad nacional española se ha articulado de forma difusa y ambigua. La problematicidad de la identidad nacional española ha sido ampliamente analizada, tanto en lo que concierne a la ciudadanía como a los partidos políticos. Más recientemente, la tensión territorial creciente a raíz de la intensificación de las reivindicaciones independentistas en Cataluña ha hecho que el nacionalismo español haya alcanzado un grado de protagonismo sin precedentes. Todo ello parece indicar que sí existía un terreno abonado para la exteriorización del nacionalismo español, que solo ha necesitado un catalizador (en este caso, el independentismo catalán), para adquirir mayor relevancia y exteriorizarse. Vox se inscribe en esta dinámica, en la que el españolismo radical adquiere fuerza al oponerse a una otredad interna (el independentismo en mayor medida; el izquierdismo y el feminismo, en menor medida) que cuestiona su pilar central: la unidad nacional. El caso español muestra cómo las cuestiones identitarias son también objeto de las coyunturas sociopolíticas concretas y no solo de los procesos históricos de largo recorrido, pudiendo verse alteradas de forma súbita y volátil.

Un rasgo determinante del marco de la excepcionalidad es que no solo valora la ausencia de ultraderecha como algo excepcional, sino que va más allá al afirmar que esta será estable e indefinida. Lo que en origen nace como un simple diagnóstico (es decir, la asunción de la excepcionalidad y las teorías 
explicativas al respecto), pronto muta en un discurso prescriptivo que cualitativamente va un paso más allá al afirmar que España es inmune y refractaria a la ultraderecha. La idea de inmunidad implica en cierto modo una determinada proyección temporal y una connotación afectiva: quien es inmune está seguro, a salvo de un peligro de forma indefinida. Esta afirmación de la inmunidad ha tenido unas implicaciones sociopolíticas determinadas, de tal manera que la ausencia de una ultraderecha fuerte ha sido interpretada como prueba de la incontestable madurez de la democracia espańola y del carácter modélico de la Transición. Esta lectura - aparte de poseer de un sesgo ideológico evidente- tiene un problema de raíz al considerar a la ultraderecha como un elemento extrínseco cuyos valores son totalmente ajenos a la democracia liberal. Aunque la ultraderecha no haya tenido éxito electoral durante una larga etapa, muchos de sus valores han estado (y están) ampliamente difundidos, aunque de forma más moderada, entre la sociedad y los partidos establecidos. Es decir, estrictamente no existe un antagonismo absoluto entre la ultraderecha, por un lado, y la democracia liberal y los actores consolidados, por otro. La ultraderecha es, más bien, un actor situado en los claroscuros de la democracia liberal, reflejo de sus tensiones y contradicciones.

En conclusión, el paradigma hegemónico para abordar el caso español ha descansado durante mucho tiempo en la idea de excepcionalidad e inmunidad. La reciente irrupción de Vox ha puesto de manifiesto los déficits de este marco explicativo. Como aquí se ha intentado demostrar, este planteamiento descansa en buena medida en una concepción estática y mecanicista sobre los procesos causales que intervienen en el desempeño de la ultraderecha: sobredimensionando la importancia de las teorías de la demanda y subestimando la volatilidad de algunos factores del lado de la oferta. Al mismo tiempo, el paradigma de la excepcionalidad se ha transformado en un discurso de carácter normativo utilizado para ensalzar la calidad de la democracia en Espańa; sin embargo, esta lectura descansa en la consideración errónea de la ultraderecha como actor totalmente ajeno a la democracia liberal.

\section{NUEVAS ESTRATEGIAS DE INVESTIGACIÓN PARA EL ESTUDIO DE LA ULTRADERECHA EN ESPAÑA}

Por último, en vista de las limitaciones del paradigma de la excepcionalidad, se apuntará un conjunto de estrategias alternativas de cara a orientar teórica y metodológicamente la agenda de investigación sobre la ultraderecha en España (susceptibles, además, de ser implementado en la investigación comparada). 
En primer lugar y de manera global, es necesario un giro epistemológico para dejar de considerar a la ultraderecha como un fenómeno extrínseco a la democracia liberal que solo emerge en escenarios críticos y extremos. Por el contrario, un enfoque más amplio y flexible puede ayudar a entender cómo la ultraderecha aparece imbricada en algunas de las problemáticas centrales que afrontan las sociedades y las democracias liberales actuales (Mudde, 2010). Por tanto, asumirla como una suerte de patología cuya aparición se explica únicamente por condiciones críticas es un error si se intenta abordar la ultraderecha de forma rigurosa (principalmente, porque esta afirmación encuentra un respaldo empírico muy limitado).

Este giro epistemológico en un campo muy cargado normativamente y objeto de grandes tensiones tiene varias implicaciones inmediatas. Por un lado, significa acabar con la distintividad y excepcionalismo con que buena parte de la academia aborda el estudio de la ultraderecha. Muchas investigaciones en la materia evitan utilizar las teorías y herramientas consolidadas en las ciencias sociales bajo la idea de que usarlas contribuye a la legitimación de la ultraderecha. Sin embargo, esta excepcionalidad no tiene base empírica o teórica y es fruto de un sesgo normativo, de forma que si se quiere avanzar en el estudio científico de este fenómeno hay que abordarlo del mismo modo con el que se estudia el resto de actores. En esta misma línea se manifiestan Mudde $(2007,2010)$ o Acha $(2017 a)$, apostando por un abordaje desde la neutralidad científica y no desde la contienda ideológica.

Otra estrategia alternativa pasa por integrar de forma más equilibrada las teorías de la demanda y de la oferta. No se trata de rechazar de lleno las teorías de la demanda, sino más bien matizar sus mecanismos y orientaciones, ya que tradicionalmente han sido sobredimensionadas y asumidas de forma acrítica. $Y$ es que el marco explicativo dominante de inspiración psicologicista, que toma como referencia principal a la Europa de entreguerras, no encuentra respaldo empírico en buena parte de los escenarios actuales. Como señala Mudde, las teorías de la demanda pueden explicar la existencia y la naturaleza del potencial electorado de la ultraderecha, pero no pueden dar cuenta de por qué algunos partidos tienen éxito y otros fracasan (2007: 230). Por eso, si la variable dependiente es el desempeño electoral, hay que otorgar más peso a los factores de la oferta: situando a la ultraderecha en el centro de la discusión —es decir, profundizando en los enfoques party-centered - y prestando atención a las estrategias que se desarrollan entre esta y el resto de partidos. A su vez, esto supone adoptar un enfoque de la agencia que permita entender cómo la ultraderecha no es un actor sometido totalmente a los procesos estructurales, sino que posee cierto margen de maniobra para intervenir en su propio rumbo.

Desde esta premisa, la irrelevancia de la ultraderecha espańola puede leerse como consecuencia de la capacidad del centroderecha establecido (AP y 
luego PP) para canalizar satisfactoriamente una serie de tendencias y pulsiones ideológicas concretas. Del mismo modo, en el reciente éxito de la ultraderecha cabe considerar la pérdida de crédito del PP ante buena parte de su electorado, unido a la existencia de una oferta atractiva (Vox) capaz de aprovechar un escenario de polarización y tensión territorial. Es decir, del caso español puede extraerse un hallazgo valioso de cara a enriquecer el corpus teórico sobre la materia: la importancia de los factores de la oferta política en el desempeño de la ultraderecha. El caso de Vox muestra cómo la oferta puede potenciar la demanda: cómo la existencia de una organización lo suficientemente asentada y con un marco ideológico eficaz es capaz de generar apoyo que anteriormente era escaso o se canalizaba por otras vías.

En esta línea, una agenda de investigación renovada sobre la ultraderecha en España deberá considerar con especial atención dos tipos de factores de la oferta: la estructura de oportunidades políticas (es decir, el conjunto de procesos y dinámicas que orientan la competición) y los factores organizativos internos (relacionados con el proceso de construcción partidista: liderazgo, perfil de la militancia, estructura organizativa, etc.), claves para las fases de irrupción y consolidación, respectivamente. Por un lado, hay que examinar las estrategias con que los partidos establecidos enfrentan la irrupción del nuevo actor, y al mismo tiempo estudiar qué consecuencias tiene esta irrupción para el resto de la familia de la ultraderecha. Además, cabe atender a los factores organizativos internos, infradesarrollados en la literatura a pesar de que se ha demostrado su papel clave para que estos partidos consigan persistencia temporal (De Lange y Art, 2011). Estos factores internos, conectados con un enfoque de la agencia, son los que principalmente pueden dar cuenta de las variaciones de desempeño de la ultraderecha en contextos concretos (es decir, de las variaciones intracaso que caracterizan a países como España).

La tercera de las vías propuesta consiste en profundizar en la caracterización ideológica de la ultraderecha emergente uniendo la fundamentación empírica con el desarrollo teórico y conceptual. Esto significa que hay que acudir a las fuentes empíricas concretas (programas electorales, discursos de élites, documentos oficiales del partido, etc.) y no aplicar de forma acrítica unos esquemas conceptuales que, aunque acertados en otros contextos, pueden no dar cuenta del caso español. Por ejemplo, Vox ya ha sido caracterizado con una pléyade de términos de dudoso encaje para el caso, pero con gran efectividad retórica: fascista, neofascista, postfascista, populista, etc. (Álvarez-Benavides, 2018). A su vez, la investigación debe ser capaz de identificar qué hay de común y de específico en los planteamientos de la emergente ultraderecha española. Todo apunta, por ejemplo, que el cariz populista existente en otras expresiones de la ultraderecha europea es menor en el caso de Vox, probablemente por el origen de sus fundadores — provenientes de la élite 
política y económica- y por la influencia de la tradición elitista en la ultraderecha española (Acha, 2019).

En cuarto lugar, el estudio de la base electoral de la ultraderecha en España debe plantearse en perspectiva comparada para comprobar si se dan procesos que han tenido lugar en otros países (por ejemplo, la proletarización de su electorado) o, por el contrario, las pautas son diferentes. Por el momento, todo parece apuntar que los principales apoyos de Vox no proceden de sectores populares, sino de las clases acomodadas; al mismo tiempo, las orientaciones antiinmigración parecen jugar un papel secundario en el voto, siendo los factores explicativos determinantes los relacionados con la organización territorial y la crisis catalana (Turnbull-Dugarte, 2019). Sin duda, esto está relacionado con la inexistencia de un mercado electoral antiinmigración rentable en España, como han señalado Morales et al. (2015). De ahí que Vox muestre una capacidad adaptativa: priorizando una narrativa de enfrentamiento con base en una otredad interna (el independentismo, principalmente, y el feminismo y el izquierdismo, en menor medida) sobre el habitual eje antiinmigración, central para la ultraderecha.

Por último, y como corolario de este conjunto de estrategias alternativas, la renovada agenda sobre la ultraderecha deberá tener necesariamente una perspectiva histórica, siendo su principal objetivo alcanzar una explicación sistemática sobre la pauta que caracteriza a esta familia de partidos en el caso español: su desigual rendimiento electoral (territorial y temporal). De este fenómeno político de largo recorrido, Vox es una expresión más, aunque posiblemente la más relevante. No obstante, si anteriormente se ha demostrado que las bases que sustentaban la supuesta excepcionalidad del caso español eran volátiles, lo mismo sucede ahora a la hora de asumir la presencia de este nuevo actor como indefinida. Su consolidación temporal dependerá de múltiples factores (principalmente, relacionados con la oferta política), por lo que parece aconsejable adoptar cierta cautela sobre Vox.

En conclusión, se ha intentado demostrar cómo el paradigma dominante sobre la ultraderecha en España (basado en la idea de excepcionalidad e inmunidad) presenta diversos déficits que se han revelado aún más evidentes con la reciente irrupción de Vox. A partir del examen crítico de este enfoque hegemónico se ha propuesto una serie de estrategias de investigación de cara a enriquecer el corpus teórico sobre la materia.

\section{Bibliografía}

Acha, B. (2017a). Nuevos partidos de ultraderecha en Europa Occidental: el caso de los Republikaner alemanes en Baden-Württemberg [tesis doctoral]. Universidad Autónoma de Madrid. 
- (2017b). La relación de la crisis económica con el ascenso de los partidos de extrema derecha: el caso de las elecciones europeas de 2014. Inguruak: Revista Vasca de Sociología y Ciencia Política, 63, 1-18.

- (2019). No, no es un partido (neo)fascista. Agenda Pública, 06-01-2019. Disponible en: http://bit.ly/2MMiiEA.

Adorno, T., Else, D. y Sanford, N. (1969). The Authoritarian Personality. New York: W.W. Norton.

Aguilar, P. (2001). Justice, Politics, and Memory in the Spanish Transition. En A. Barahona de Brito, C. González-Enríquez y P. Aguilar (eds.). The Politics of Memory: Transitional Justice in Democratizing Societies (pp. 92-119). Oxford: Oxford University Press. Disponible en: https://doi.org/10.1093/0199240906.003.0004.

Alonso, S. y Rovira, C. (2015). Spain: No Country for the Populist Radical Right? South European Society and Politics, 20 (1), 21-45. Disponible en: http://dx.doi.org/10.1080/1360 8746.2014.985448.

Álvarez-Benavides, A. (2018). Fascisms 2.0: the case of Spanish. DigitCult: Scientific Journal on Digital Cultures, 3 (3), 61-74. Disponible en: http://dx.doi.org/10.4399/97888255208976.

Antón, J. (2009). Las concepciones nucleares, axiomas e ideas-fuerza del fascismo clásico (1919-1945). Revista de Estudios Politicos, 146, 49-79.

Art, D. (2011). Inside the radical right: the development of anti-immigrant parties in Western Europe. Columbia: University of South Carolina Press. Disponible en: https://doi. org/10.1017/CBO9780511976254.

Arzheimer, K. (2018). Conceptual Confusion Is Not Always a Bad Thing: The Curious Case of European Radical Right Studies. En M. Roseneck, A. Schmitt y J. Sirsch (eds.). Demokratie Und Entscheidung (pp. 23-40). Wiesbaden: Springer. Disponible en: https:// doi.org/10.1007/978-3-658-24529-0_3.

Casals, X. (1994). Neonazisme a Espanya, 1966-1992 [tesis doctoral]. Universidad de Barcelona.

- (2009). La renovación de la ultraderecha española: una historia generacional (19662008). Historia y Politica, 22, 233-258.

De Lange, S. y Art, D. (2011). Fortuyn versus Wilders: An Agency- Based Approach to Radical Right Party Building. West European Politics, 34 (6), 1229-1249. Disponible en: https://doi.org/10.1080/01402382.2011.616662.

Del Río, M.A. (2013). De la extrema derecha neofranquista a la derecha conservadora: los orígenes de Alianza Popular (1973-1979) [tesis doctoral]. Universitat Autónoma de Barcelona.

Duñaiturria, G. (2017). Análisis de las causas de la irrelevancia de una derecha radical populista en España (1987-2015). Una excepción en el contexto europeo [tesis doctoral]. Universidad Camilo José Cela.

Eatwell, R. (2003). Ten theories of the extreme right. En P. Merkl y L. Weinberg (eds.). RightWing Extremism in the Twenty-first Century (pp. 45-70). London: Frank Cass.

Fuerza Nueva (1976). Programa politico de Fuerza Nueva. Disponible en: https://elpais.com/ diario/1976/07/15/espana/206229605_850215.html.

Gilmour, J. (1992). The Extreme Right in Spain. Blas Piñar and the Spirit of the National Uprising. En P. Hainsworth (ed.). The Extreme Right in Europe and the USA (pp. 206-231). London: Pinter. 
Gómez-Reino, M. y Llamazares, I. (2018). Populism in Spain: the role of ideational change in Podemos. En K. A. Hawkins, R. Carlin, L. Littvay y C. Rovira (eds.). The Ideational Approach to Populism: Concept, Theory and Analysis (pp. 320-336). London: Routledge. Disponible en: https://doi.org/10.4324/9781315196923-13.

González-Enríquez, C. (2017). The Spanish Exception: Unemployment, inequality and immigration, but no right-wing populist parties. Working Paper Real Instituto Elcano, 3.

Griffin, R. (2000). Interregnum or endgame? The Radical Right in the «Post-Fascist» Era. Journal of Political Ideologies, 5 (2), 163-78. Disponible en: http://dx.doi.org/10.1080/713682938.

Hernández-Carr, A. (2012). La irrupción de la nueva extrema derecha en España: un análisis de la trayectoria, estrategia politica y base electoral de Plataforma Per Catalunya [tesis doctoral]. Universidad Autónoma de Barcelona.

Ignazi, P. (2003). Extreme right parties in Western Europe. Oxford: Oxford University Press. Disponible en: https://doi.org/10.1093/0198293259.001.0001.

INE. Encuesta de Población Activa. Disponible en: http://www.ine.es/jaxiT3/Datos.htm?t=4247.

Llamazares, I. (2012). La communauté nationale menacée. Inertie et transformations de l'idéologie ultranationaliste de l'extrême droite espagnole. En A. Fernández. y M. Petithomme (eds.). Les nationalismes dans l'Espagne contemporaine (1975-2011). Compétition politique et identités nationales (pp.77-102). Paris: Armand Colin.

- y Ramiro, L. (2006). Les espaces politiques restreints de la droite radicale espagnole. Une analyse des facteurs politiques de la faiblesse de la nouvelle droite en Espagne. Pôle Sud, 25, 1262-1676. Disponible en: https://doi.org/10.3917/psud.025.0137.

López, A. I. (2017). España 2000, la evolución de la derecha radical valenciana (2003-2015) [tesis doctoral]. Universitat de València.

Mudde, C. (1996). The War of Words Defining the Extreme Right Party Family. West European Politics, 19 (2), 225-248. Disponible en: https://doi.org/10.1080/01402389608425132. (2007). Populist Radical Right Parties in Europe. Cambridge: Cambridge University Press. (2010). The Populist Radical Right: A Pathological Normalcy. West European Politics, 33 (6), 1167-1186. Disponible en: https://doi.org/10.1080/01402382.2010.508901.

Morales, L., Pardos-Prado, S. y Ros, V. (2015). Issue emergence and the dynamics of electoral competition around immigration in Spain. Acta Politica, 50 (4), 461-485. Disponible en: https://doi.org/10.1057/ap.2014.33.

Muñoz, J. (2008). From National Catholicism to Democratic Patriotism? An empirical analysis of contemporary of Spanish national identity [tesis doctoral]. Universitat Pompeu Fabra.

Norris, P. (2005). Radical Right: Voters and Parties in the Electoral Market. Cambridge, Cambridge University Press. Disponible en: https://doi.org/10.1017/CBO9780511615955.

Reich, W. (1972). Psicología de masas del Fascismo. Madrid: Editorial Ayuso.

Rinken, S. (2016). Economic crisis and anti-immigrant sentiment: the case of Andalusia. Revista Española de Investigaciones Sociológicas, 156, 77-96. Disponible en: http://dx.doi. org/10.5477/cis/reis.156.77.

Rodríguez, J. L. (1992). La extrema derecha en España: del tardofranquismo a la consolidación de la democracia [tesis doctoral]. Universidad Complutense de Madrid. Disponible en: https://doi.org/10.18356/41a60d5f-es.

Rodríguez, J. L. (1997). La extrema derecha española en el siglo XX. Madrid: Alianza Universidad. 
Ruiz-Carnicer, M. A. (ed.) (2013). Falange. Las culturas politicas del fascismo en la España de Franco (1936-1975). Zaragoza: Institución Fernando El Católico.

Ruzza, C. (2018). The radical right in Southern Europe. En J. Rydgren (ed.). The Oxford Handbook of the Radical Right (pp. 505-520). Oxford: Oxford University Press. Disponible en: https://doi.org/10.1093/oxfordhb/9780190274559.013.25.

Rydgren, J. (2007). The sociology of the radical right. Annual Review of Sociology, 33, 241-262. Disponible en: https://doi.org/10.1146/annurev.soc.33.040406.131752.

Sánchez-Cuenca, I. (2018). Vox y nacionalismo español», Infolibre. Disponible en: https:// www.infolibre.es/noticias/opinion/columnas/2018/12/05/vox_nacionalismo_espanol_ 89529_1023.html.

Turnbull-Dugarte, S. J. (2019). Explaining the end of Spanish exceptionalism and electoral support for Vox. Research and Politics, 6 (2), 1-8. Disponible en: https://doi. org/10.1177/2053168019851680. 